\title{
Sentidos e métodos de territorialização na atenção primária à saúde
}

\author{
Meanings and methods of territorialization in primary health care
}

Vanira Matos Pessoa ${ }^{1}$

Raquel Maria Rigotto ${ }^{1}$

Fernando Ferreira Carneiro ${ }^{2}$

Ana Cláudia de Araújo Teixeira ${ }^{1}$

${ }^{1}$ Departamento de Saúde Comunitária, Centro de Ciências da Saúde, Universidade Federal do Ceará. R. Prof. Costa Mendes $1608 / 5^{\circ}$, Rodolfo Teófilo. 60431-970 Fortaleza CE.

vanirapessoa@gmail.com ${ }^{2}$ Faculdade de Ciências da Saúde, Departamento de Saúde Coletiva,

Universidade de Brasília.

\begin{abstract}
Territorially-based participative analytical methodologies taking the environmental question and work into consideration are essential for effective primary health care. The study analyzed work and environment-related processes in the primary health care area and their repercussions on the health of workers and the community in a rural city in Ceará, whose economy is based on agriculture for export. It sought to redeem the area and the proposal of actions focused on health needs by the social subjects through the making of social, environmental and workrelated maps in workshops within the framework of action research. Examining the situation from a critical perspective, based on social participation and social determination of the health-disease process with regard to the relations between production, environment and health, was the most important step in the participative map-making process, with the qualitative material interpreted in light of discourse analysis. The process helped identify the health needs, the redemption of the area, strengthened the cooperation between sectors and the tie between the health of the worker and that of the environment, and represented an advance towards the eradication of the causes of poor primary health care services.
\end{abstract}

Key words Primary health care, Workers $1 / 4$ health, Environmental health, Determination of health needs
Resumo Metodologias analíticas participativas de base territorial são essenciais para a atuação da Atenção Primária à Saúde (APS) considerando a questão ambiental e o trabalho. Este estudo, realizado em município cearense com modelo de produção agroexportador, analisou os processos no território da APS relacionados ao ambientel trabalho e as repercussões sobre a saúde da comunidade e dos trabalhadores, com vistas à reapropriação do território e proposição de ações focadas nas necessidades de saúde, pelos sujeitos sociais, a partir da elaboração dos mapas: social, ambiental e do trabalho em oficinas conduzidas em pesquisa-ação. A problematização na perspectiva crítica, embasada na participação social e na determinação social do processo saúde-doença referente às relações produção-ambiente-saúde foi etapa fundamental no mapeamento participativo, tendo sido o material qualitativo interpretado à luz da análise do discurso. O processo favoreceu a identificação das necessidades de saúde, a reapropriação do território reforçando a atuação intersetorial, fortalecendo a interlocução entre a saúde ambiental e do trabalhador, avançando na superação dos processos contribuintes para a insuficiência das práticas da APS.

Palavras-chave Atenção Primária à Saúde, Saúde do trabalhador, Saúde ambiental, Determinação das necessidades de saúde 


\section{Introdução}

O modelo de desenvolvimento econômico promove impactos no modo de vida das comunidades e trabalhadores, tanto nos contextos rurais quanto urbanos, gerando agravos à saúde decorrente das alterações ambientais e da organização do trabalho. Dias et al. ${ }^{1}$, apontam que as relações produção, ambiente e saúde são determinadas pelo modo de produção e consumo, consistindo na principal referência para a compreensão das condições de vida, do perfil de adoecimento e morte e a vulnerabilidade diferenciada dos segmentos sociais e a degradação ambiental. Para Dias et al. ${ }^{1}$ e Pessoa et al. ${ }^{2}$ o enfoque do território na Atenção Primária à Saúde (APS) permite delinear e caracterizar a população e seus problemas de saúde, a criação de vínculo e responsabilidade entre os serviços de saúde e usuários propiciando o acesso dos usuários-trabalhadores ao serviço, bem como a avaliação dos impactos das ações.

Apesar disso, as categorias trabalho e ambiente continuam pouco abordadas na prática, sendo um desafio à efetivação das políticas de saúde ambiental e do trabalhador na APS. A ampliação da ação da APS visando à incorporação da questão ambiental e do trabalho na identificação das necessidades de saúde é cada vez mais necessária, e, para tal, é essencial discutir a concepção de território que ancora a política de saúde, entremeando-a ao contexto social, econômico, político, cultural e ideológico, bem como propor metodologias analíticas participativas de base territorial, considerando que a leitura integrada do espaço social necessita de uma visão de território, concebendo o espaço como um híbrido entre sociedade e natureza, entre política, economia e cultura, e entre materialidade e "idealidade", numa complexa interação tempo-espaço. A noção híbrida é múltipla e nunca indiferenciada do espaço geográfico, o território é concebido na imbricação de múltiplas relações de poder, do poder mais material das relações econômicopolíticas ao poder mais simbólico das relações de ordem mais estritamente cultural ${ }^{3}$.

A Política Nacional de Atenção Básica ${ }^{4}$ estabelece como atribuições comuns a todos os profissionais: participar do processo de territorialização e mapeamento da área de atuação da equipe, identificando grupos, famílias e indivíduos expostos a riscos, inclusive aqueles relativos ao trabalho, e da atualização contínua dessas informações, priorizando as situações a serem acompanhadas no planejamento local. Logo, a territorialização é uma ação primordial, pois dela decorre a análise da situação de saúde, planejamento e a implantação de ações estratégicas, que garantam resolubilidade ao sistema. Também a Política Nacional de Promoção da Saúde ${ }^{5}$ considera prioritária a promoção do uso de metodologias de reconhecimento do território, em todas as suas dimensões: demográfica, epidemiológica, administrativa, política, tecnológica, social e cultural, como instrumento de organização dos serviços de saúde.

Por outro lado, as políticas norteadoras do processo de trabalho na APS orientam a realização de ações para grupos específicos como: criança, adulto, idoso, mulher, trabalhador. Isto contribui para a fragmentação das ações na rotina dos serviços, que têm sido organizados priorizando a assistência, com ações programáticas, com pouco enfoque na integralidade da atenção e na promoção da saúde. Esta focalização das ações contribui para que os profissionais não incorporem em suas práticas as dimensões do trabalho e ambiente, embasada na compreensão ampliada de saúde e de território.

A incorporação dos processos que modificam as relações humanas no e com o território nas práticas da APS apresentam-se insuficientes, sendo que a territorialização restringe-se a elaboração de um mapa que focaliza áreas de risco entendidas como responsabilidade dos profissionais da APS, e mais como uma estratégia organizativa e gerencial do serviço, não incorporando realmente a participação comunitária, não sedimentando o compromisso ético-sanitário da equipe com a população, nem estabelecendo parcerias que busquem ação corresponsável na promoção da mudança. Contudo, o contexto da reestruturação produtiva das novas relações de trabalho e as transformações ambientais têm gerado novas necessidades de saúde e demandado novas práticas sanitárias na APS.

Os autores apontam que o ponto de partida para a organização dos serviços e das práticas de vigilância em saúde é a territorialização do sistema local de saúde [...] segundo a lógica das relações entre condições de vida, ambiente e acesso às ações e serviços de saúde ${ }^{6}$. Reconhecer o território sob responsabilidade dos trabalhadores de cada setor como estratégia para o planejamento de suas ações já está suficientemente proposto, o que tem se apresentado como desafios são os métodos utilizados para o processo de desvelamento do território. Daí surgem algumas perspectivas como os mapas falantes e mapas vivos, com a descrição de experiências singulares em escolas e na APS?. 
Goldstein e Barcellos ${ }^{8}$ sugerem que os métodos de mapeamento podem ser utilizados como instrumento didático e de debate com a população leiga sobre suas condições socioeconômicas e a inserção em seu território. Ressaltam que os mapas devem ser pensados e produzidos a partir de um processo educativo por parte dos pesquisadores e população, na busca de um melhor conhecimento sobre o território, os determinantes e os condicionantes ambientais e sociais e sua influência no desenvolvimento dos agravos de saúde da população.

As técnicas participativas para definir a percepção geográfica de espaço servem para compartilhar os conhecimentos gerados de maneira conjunta sobre cada região, permitindo agregar novas informações que muitas vezes não estão presentes nas bases de dados oficiais. Acreditamos estar em consonância com os autores quando propomos que o 'mapeamento participativo', necessita de uma etapa de problematização crítica da realidade, no processo de leitura e interpretação dos mapas.

Apesar do esforço empreendido na prática da APS na realização da territorialização em saúde, seja no modelo tradicional, seja nos mapas vivos, ou falantes, há uma lacuna consistente em publicações científicas, que subsidiem os profissionais da APS na realização de territorialização em saúde que possibilite identificar, analisar $e$ propor ações individuais e coletivas considerando a determinação social da doença. Breilh ${ }^{9}$ explicita a diferença entre o que se concebe por determinantes sociais da saúde e determinação social da saúde. Segundo o autor, a primeira concepção objetiva encontrar as causas das causas dos problemas de saúde, enquanto que a segunda trata não dos fatores causadores, mas dos processos históricos que geram os problemas de saúde coletiva. Adotando esta perspectiva, inferimos que o território na práxis da APS precisa ser desvelado pelos profissionais e comunidades além dos limites das áreas adscritas e dos problemas emergenciais que alteram a vida das pessoas. À luz destes pressupostos apresentamos um mapeamento participativo em saúde ambiental e do trabalhador na APS, que objetivou: identificar e analisar os processos no território da APS relacionados ao ambiente e trabalho e as repercussões sobre a saúde da comunidade e dos trabalhadores, com vistas à reapropriação do território e proposição de ações centradas nas necessidades de saúde.

\section{Metodologia}

Ancorados na abordagem qualitativa conforme Minayo et al. ${ }^{10}$ ao destacar que a realidade social é o próprio dinamismo da vida individual e coletiva com toda a riqueza de significados dela transbordante, utilizamos o método da pesquisa-ação que segundo Thiollent ${ }^{11}$ é um "[...] tipo de pesquisa social com base empírica concebida e realizada em estreita associação com uma ação ou com a resolução de um problema coletivo e no qual os pesquisadores e os participantes representativos da situação ou do problema estão envolvidos de modo cooperativo e colaborativo".

A pesquisa-ação realizada em 2010, em Quixeré, Ceará, Brasil, ocorreu no formato de oficinas, a cada 21 dias com duração média de oito horas, totalizando 44 horas. Trata-se de um território marcado por profundas transformações socioambientais na última década, a partir da instalação empresas transnacionais de fruticultura irrigada para exportação ${ }^{12}$.

Para a composição do grupo de pesquisa formado por 14 sujeitos, adotou-se como critério a participação social e a representatividade do território local nos segmentos: políticas públicas, poder público e movimentos sociais, considerando ainda o interesse dos agentes locais em debater as questões referentes às relações produçãoambiente-saúde e disponibilidade dos mesmos em participar da pesquisa. No processo de constituição do grupo, foi pactuado, a partir da solicitação dos sujeitos, como condição para a adesão e participação dos mesmos, que o discurso seria analisado como um produto coletivo. Desse modo, o grupo foi composto por: ESF - com área de abrangência urbano e rural (médico, enfermeiro, agente comunitário de saúde, auxiliar de enfermagem), dois usuários do SUS residentes no campo (identificados pelos movimentos sociais), um trabalhador rural do agronegócio (indicado pela Associação dos Trabalhadores Rurais), o presidente da Associação dos Trabalhadores Rurais, uma conselheira municipal de saúde do segmento usuário, um vereador residente na comunidade, uma auxiliar de serviços gerais, uma professora da escola municipal e dois representantes dos movimentos sociais, tendo sido estes últimos indicados por seus pares.

Como inquietações iniciais sobre o 'mapeamento participativo em saúde’ tínhamos as seguintes questões: qual a utilidade (entendida como os sentidos, significados apreendidos) no processo do grupo e a finalidade (compreendida como os fins, para que fazer) da territorialização 
em saúde para a comunidade e para APS? Qual a metodologia mais adequada para realizar uma territorialização em saúde que evidencie as necessidades de saúde concebendo as relações produção-ambiente-saúde? Estas indagações nos impulsionaram a ancorarmos o desenvolvimento do 'mapeamento participativo' descrito neste manuscrito nos ensinamentos de Paulo Freire ${ }^{13}$.

“[...] toda compreensão de algo corresponde cedo ou tarde, uma ação. Captado um desafio, compreendido, admitidas as hipóteses de resposta o homem age. A natureza da ação corresponde à natureza da compreensão. Se a compreensão é crítica ou preponderantemente crítica, ação também o será. Se é mágica a compreensão, mágica será a ação". Em consonância com Paulo Freire valorizamos a etapa de problematização tentando nos distanciar da superficialidade e ampliar, modificar e aprofundar a compreensão crítica dos processos vividos no território local, para a proposição de soluções.

Embasados em Thiollent ${ }^{11}$ e Freire ${ }^{13}$ conduzimos as oficinas entendendo tanto o sujeito como o objeto como construções sócio-históricas que precisam ser problematizadas e desfamiliarizadas, o que implica na problematização da realidade ${ }^{13}$. Zanotto e De Rose ${ }^{14}$, interpretando Paulo Freire, sublinham que a ação de problematizar acontece a partir da realidade que cerca o sujeito; a busca de explicação e solução visa a transformar aquela realidade, pela ação do próprio sujeito (sua práxis). O sujeito, por sua vez, também se transforma na ação de problematizar e passa a detectar novos problemas na sua realidade e assim sucessivamente.

Considerando os pressupostos teóricos, a condução das oficinas foi realizada da seguinte forma: a) exposição oral com fotos, do passado e do presente do território, por pessoas da comunidade selecionadas pelo grupo de pesquisa; b) elaboração de mapas representativos da dinâmica social, ambiental e do trabalho do território, em subgrupos; c) submissão dos mapas a análise crítica dos demais sujeitos integrantes do grupo de pesquisa; d) problematização realizada pela pesquisadora, após o esgotamento das considerações feitas pelos participantes acerca dos mapas apresentados. Nesta fase indagamos como se relacionavam os elementos contidos em cada mapa entre si e com a saúde, tais como: transformações ambientais e a relação com a saúde; $m u$ danças no modo de vida e implicações na saúde; transformações no trabalho e alterações na saúde, desenvolvimento econômico e a relação com a qualidade de vida.
Adotamos a Análise do Discurso que, segundo Orlandi ${ }^{15}$ consiste na extração dos sentidos dos textos, considerando que a linguagem, enquanto trabalho simbólico não é transparente, mas parte do trabalho social geral, constitutivo do homem e da sua história. Quanto aos procedimentos de análise, o grupo analisava os mapas que elaboraram, mas os discursos do grupo acerca do processo foram analisados pela pesquisadora, sendo posteriormente apresentado ao grupo, para 'validação' da análise. A pesquisa foi desenvolvida conforme a Resolução no 196/96, do Conselho Nacional de Saúde ${ }^{16}$ aprovada pelo Comitê de Ética em Pesquisa da Universidade Federal do Ceará.

\section{Resultados e discussão}

\section{O processo de mapeamento participativo em saúde ambiental e do trabalhador na APS}

O 'mapeamento participativo' descrito neste artigo utiliza como mediador a elaboração de mapas, contudo para identificar necessidades de saúde centradas na comunidade considera a determinação social da doença, intersetorialidade, a percepção de coletivos, a dinamicidade do território. Este mapeamento consiste num processo reflexivo e crítico, que incorpora as dimensões socioafetivas, simbólicas, culturais, como também as transformações territoriais e do modo de vida, advindas com a reestruturação produtiva e a questão ambiental.

Inicialmente, o grupo identificou de onde vieram, porque vieram e como viviam os primeiros habitantes do lugar, descobriram que o povoamento da região esteve relacionado a questões ambientais, como as enchentes, que contribuíram para a migração de pessoas, iniciandose o processo de povoamento da região.

[...] Os mais idosos dizem que em 1880 já existia ranchos de madeiras cobertos de palha em cima da serra [...]. Vieram [...] devido às enchentes. Esse foi um dos fatores que fizeram com que as famílias viessem para cá. Em 1920 foi a chegada dos primeiros habitantes.

Resgatou-se como era o modo de vida e como as pessoas se relacionavam com o lugar, e como foi o povoamento da região, bem como sua relação com as questões ambientais. Apesar de trabalhar há mais de três anos neste lugar os profissionais da APS desconheciam esses aspectos singulares, importantíssimos para a realização de 
ações de abordagem familiar, comunitária e de saúde ambiental. Evidenciou-se a necessidade da valorização da cultura e do vínculo afetivo das pessoas com o território pelo serviço de saúde.

Estudo empírico realizado por Carvalho ${ }^{17}$ numa Unidade Básica de Saúde (UBS) considerando o quanto e como a equipe saúde da família (ESF) compreende a complexidade territorial e de que maneiras suas práticas assistenciais configuram estratégias reforça que o processo de territorialização na UBS não apreende as relações de poder e as ligações simbólico-afetivas que configuram a complexidade do território local, já que a base conceitual ancora-se nos preceitos da geografia tradicional e da geografia quantitativa, em que há o entendimento da noção de espaço absoluto naturalizado, reconhecendo o Estado como detentor do poder de demarcar os limites da territorialidade ${ }^{17}$.

O autor aponta que se soma a isso a supervalorização da epidemiologia para o reconhecimento da realidade tendendo-se, portanto, a um planejamento normativo. No intuito de avançarmos e superarmos o desafio exposto por Carvalho, optamos por um mapeamento participativo com a elaboração de três mapas para aprofundarmos a problematização das dimensões do ambiente e trabalho, e possibilitar a visualização do território na complexidade em que ele se apresenta, a partir de recortes distintos. Coube ao grupo a responsabilidade de desenhar os mapas, sem georreferenciamento ou utilização de outros mapas existentes. Essa escolha relacionou-se a alguns fatores que consideramos importantes: primeiramente, a participação ativa de todos em todas as fases do processo era fundamental, e no grupo, havia participantes não alfabetizados, e a elaboração do mapa, conforme proposto não os excluía de participar do reconhecimento do território; em segundo lugar, a necessária valorização dos saberes, enquanto coletivos igualmente capazes de realizar o mapeamento participativo, aliando o saber popular com o saber técnicocientífico; e, finalmente, porque não dispúnhamos de tempo hábil durante o mestrado e nem de recursos financeiros para implantarmos tecnologias como georreferenciamento junto ao grupo já que o uso desta tecnologia não fazia parte do cotidiano dos sujeitos. Acreditamos também, que o desenho propicia a representação simbólica de aspectos culturais, que poderiam não estar presentes em outro tipo de mapa. No entanto, destacamos que o georreferenciamento pode trazer outros aspectos, que são essenciais para um mapeamento, que utilize o recorte da saúde ambiental e do trabalhador, entretanto não são objetos de análises neste artigo.

\section{Mapeamento participativo e os desafios na identificação das necessidades de saúde}

Neste tópico descrevemos como foi a orientação metodológica para a elaboração de cada mapa, para em seguida apresentarmos a fase analítica do processo. Assim, para a elaboração do mapa social solicitamos aos participantes que representassem a comunidade, explicitando todos os aspectos que considerassem fundamentais para a vida comunitária. O grupo explicitou as dificuldades para "mapear o território" na prática dos serviços de saúde.

[...] no Programa Saúde da Família a primeira coisa que você tem que fazer é o mapeamento da sua área, é a construção desses mapas [...]. A gente até sabe como é o mapa social [...], só que o tempo é tão pequeno [...], se fosse pegar esse mapa e fazer lá no posto, que de dez em dez minutos chega um para falar com a gente, a gente não consegue, mas a gente teria que ter esses mapas construídos, é uma coisa real.

Consideramos desafiante propor um mapeamento participativo, que entrelace a análise técnica dos profissionais da saúde acerca do território com a análise simbólica, embasada na compreensão das comunidades. Por que tal processo não pode ser realizado fora de uma proposta metodológica participativa, que problematize a realidade e como se dão esses processos na vida. Em contrapartida dispor-se a refletir com a intencionalidade de agregar novos olhares e novas perspectivas é animador para quem vivencia contextos complexos e desconhecidos; no entanto, do ponto de vista prático, requer habilidades como reconhecer e respeitar o saber popular em relação ao modo de vida e às práticas em saúde, dentre outros aspectos essenciais para a territorialização.

$\mathrm{Na}$ análise do mapa social, percebemos que os problemas identificados são a prostituição, drogas e doenças sexualmente transmissíveis, porém, os participantes não os relacionam com as mudanças impostas pelo modo de produção como elemento central na determinação social do processo saúde-doença. Nesse sentido, os agravos são enumerados somente como decorrentes da ausência ou incipiência das políticas públicas e problemas sociais vinculados à saúde. Apesar de saber que existe o trabalho, ele não é concebido como algo a ser considerado pelo setor saúde na abordagem de mapear "tudo o que é fundamental para a vida comunitária”. 
[...] vou sair triste daqui hoje porque, [...] essa questão de ter traficante na porta das escolas [...] eu até sabia que aqui rolava droga, mas na parte dos prostíbulos. [...] para mim, isso é novo, eu acho que a escola com saúde [...] urgentemente ter que trabalhar a questão das drogas dentro das escolas [...].

É área de risco [...] dos prostíbulos, [...] nessa área $[. .$.$] tem muitas residências [...] de 30$ homens que são trabalhadores que vem para empresa [...], na mesma casa [...].

Optamos em não direcionar a elaboração do mapa social para identificar áreas de risco, ou de maior vulnerabilidade, porque acreditamos que a abordagem territorial em saúde é complexa e é essencial empreender um esforço metodológico para captar as necessidades de saúde de base territorial. De acordo com o grupo de pesquisa, no que toca ao mapa social:

A gente teve um pouco de dificuldade [...] a gente foi descobrindo coisas que a gente também não sabia, um ajuda aqui e outro ali e como a gente trabalha nesse território [...] realmente tem que conhecer, [...] quais são os recursos sociais [...] para desenvolver um trabalho melhor.

A elaboração do mapa social possibilitou a descoberta de como estão às políticas públicas: quais os estrangulamentos, os nós, as perspectivas, as necessidades da comunidade, emergindo de forma bastante significativa a questão da ação intersetorial que na prática constitui-se num desafio, bem como questões sociais relacionadas à fragilidade das políticas públicas de saúde, educação, lazer e segurança pública.

A partir do mapa a gente pôde identificar todos os problemas [...], porque muitas vezes devido a nossa rotina a gente passa por cima de muitos pontos que foi descoberto hoje, [...] porque a gente sabe que existe só que a gente não sabe a dimensão de cada ponto, que foi colocado aí no mapa.

Eu posso trabalhar e apagar um foguinho aqui e acolá, que muitas vezes eu não me planejo, mas quando eu faço isso aí [o mapa], dá para se planejar e começar a fazer um plano de trabalho de como vamos trabalhar, porque tem que priorizar, é trabalho demais, [...] acho que esse mapa vai nos subsidiar para [...] fazer esse plano e ver por onde é que vamos começar, porque problemas [...] tem muito.

Evidenciamos que a elaboração do mapa social não conseguiu adentrar no mundo do trabalho. Nesse passo do mapeamento participativo, que consiste, quase sempre, na forma de realizar a territorialização em saúde adotada no cotidiano dos serviços de saúde, os problemas de saúde, ou a necessidade de ação do setor da saúde ficaram restritos às ações prioritárias na APS focali- zadas nos grupos de riscos. O trabalho só surgiu quando o grupo foi convidado a 'pensar' o trabalho, a desenhar o mapa identificando e apresentando as 'pessoas que fazem' e 'como fazem' o trabalho em cada comunidade.

É interessante notar que o grupo identificou o agricultor familiar, o trabalhador do agronegócio, o trabalhador do caju, apesar destes representarem os trabalhadores rurais, indicando que há uma percepção que o processo de produção diferencia-se, assim, como o processo saúde-doença. O grupo percebeu a importância da categoria trabalho e o reconhecimento disso como ferramenta para identificação de problemas de saúde do trabalhador, no entanto, relatou dificuldade de visualizar o trabalho, o que nos dá indícios de quão distantes estão do serviço de saúde as ações relativas à atenção aos trabalhadores. Para a elaboração desse mapa foi imprescindível a colaboração dos agentes sociais, principalmente dos trabalhadores que conheciam a teia de relações estabelecidas nesse meio.

A elaboração deste mapa propiciou a reflexão sobre o crescimento e a pobreza, bem como sobre os problemas e riscos relativos ao trabalho. Os mesmos destacaram que esse momento consistiu em uma oportunidade de descobrir os riscos e os agravos à saúde dos trabalhadores do território.

[...] todo trabalho [...] oferece um risco, [...], por exemplo, um trabalhador do campo está exposto ao sol, todo trabalho oferece seus riscos e seus benefícios e está sendo importante para gente identificar esses principais [...].

Esse passo apesar de ser considerado difícil para o grupo também contribuiu para a percepção de quão as transformações locais, o modelo de produção imposto à comunidade pouco tem se preocupado com o trabalhador, que a centralidade do modo de produção está na garantia de produto, como um ato mecânico desconsiderando a pessoa que trabalha.

Eu achei muito difícil construir esse mapa, são tantas profissões especificadas, mas se você está em um lugar fora do seu, e a pessoa pergunta: qual é a principal fonte de renda lá na sua comunidade? E aí, de repente, a gente não sabe, [...] e isso aí [elaboração do mapa] é muito bom para gente acordar [...] para ver a realidade [...] da comunidade da gente [...] os riscos, porque às vezes a pessoa trabalha, mas não se preocupa se está correndo algum risco, a preocupação é na produção. É produzir! Produzindo é o que basta, não se preocupa com o que pode acontecer com o trabalhador que está produzindo aquele alimento. 
A percepção do agronegócio e seu processo produtivo como gerador de risco dialoga com a interpretação de territorialização proposta por Santos e Rigotto ${ }^{18}$, na medida em que ressaltam a importância do mapeamento reconhecer os processos produtivos locais. Assim, uma proposta de mapeamento, que pressupõe fortalecer atuação coletiva propiciando a ampliação da visão acerca da realidade, só é possível se contar com uma estratégia metodológica indutora da criticidade, entendida de acordo com Paulo Freire:

"[...] é precisamente a criticidade a nota fundamental da mentalidade democrática. Quanto mais crítico um grupo humano, tanto mais democrático e permeável [...]. Tanto mais democrático, quanto mais ligado às condições de sua circunstância. Quanto menos criticidade em nós, tanto mais ingenuamente tratamos os problemas e discutimos superficialmente os assuntos"13.

Desse modo, para além do mapeamento há que considerarmos ferramentas que promovam a inquietude dos atores envolvidos no processo de territorialização. A depender da ação "mapear”, os resultados estariam estritos ao levantamento do conhecimento prévio ou da condensação de informações obtidas em documentos oficiais. O relato a seguir demonstra como foi significativo para o grupo desvelar o mundo do trabalho. Passaram a perceber o sentido do ser trabalhador, as contribuições para a comunidade e os riscos que envolvem as atividades de trabalho. A descrição do processo de trabalho no campo permitiu perceber que isso pode gerar danos à saúde, e que, portanto, era fundamental conhecer como as pessoas fazem o trabalho para a identificação dos riscos e estabelecer nexos causais, além de propor estratégias de promoção da saúde e prevenção de doenças.

Foi importante esse trabalho, embora tenha sido complicado, [...] se for analisar ainda está faltando alguma coisa. [...] a gente percebeu [...] os riscos que esses profissionais correm no seu trabatho e até valorizar [...]. Cada profissional [...] e a gente viu também a procedência, de onde vem esse pessoal. Então, a maioria tirando os agricultores $[. .$.$] vem de fora, [. .$.$] . Achei muito importante esse$ mapa para gente ter uma ideia de onde vêm essas pessoas, quais são os serviços que prestam aqui [...].

A sistematização das ocupações possibilitou adentrar o mundo do trabalho e as implicações no modo de vida, bem como discutir o modelo de produção e as repercussões sobre a saúde e o ambiente. Foi possível identificar as necessidades de saúde dos trabalhadores e promover uma aproximação e responsabilização pelos trabalha- dores, na medida em que se incorporou o trabalho como parte das ações da APS no território.

Para a feitura do mapa ambiental informamos ao grupo que o mesmo deveria conter os bens naturais existentes na comunidade, bem como identificar as transformações ambientais percebidas no território, caracterizando os mecanismos responsáveis por elas. O grupo evidenciou no mapa ambiental os mecanismos de transformação vividos no território decorrentes do desmatamento e das queimadas para a plantação de frutas e os grãos, o que, aliados ao uso dos agrotóxicos, têm contribuído para o surgimento de outras espécies, como as pragas.

Analisando o mapa ambiental verificamos que o grupo conseguiu identificar numerosas formas de contaminação ambiental nas comunidades: os agrotóxicos, por meio da ação do agronegócio, bem como aquelas causadas por caieiras,os fornos de padaria e os veículos que lançam poluentes atmosféricos.

Este mapa auxiliou no debate sobre as transformações percebidas no território local e de que forma isso gera impactos à saúde das pessoas do lugar, sendo possível perceber que há um processo em curso que enseja repercussões à vida. O grupo surpreendeu-se com a rapidez das transformações ocorridas no território, identificando, por exemplo, a perda da liberdade de ir e vir, pois a terra passou a ser propriedade privada do agronegócio, levando à restrição do acesso a terra por parte dos agricultores, tanto no que esta representa como base para a realização de trabalho autônomo como na forma de se relacionar com o ambiente. No que se refere a este segundo aspecto, entendemos, a partir do relato do grupo, que há perda para os camponeses do contato com a natureza que se materializa na liberdade de andar, brincar pelos campos sem medo, numa relação de convivência que gera prazer e saúde. Mas, o processo acontece de forma despercebida, que somente num processo crítico-reflexivo, percebem-se estas transformações no modo de vida decorrente de atores externos, alheios às suas relações sociais.

[...] eu moro há 26 anos aqui [...], mas quando você faz um mapa com as mudanças [...] e analisa as mudanças você fica surpresa com tanta mudança que veio e o quanto beneficiou, mas também o quanto trouxe de prejuízo [...] traz vantagens, mas também desvantagens para o seu município, para o lugar que você mora! As pessoas tinham a liberdade de correr e brincar nos campos e hoje não tem mais essa liberdade, hoje é tudo tomado de plantação!

O grupo enumerou profundas transformações no ecossistema, a partir do vivido, e relatou 
como se deu o processo de extinção de espécies vegetais e animais e suas relações com a saúde humana. Apontam que muitas espécies utilizadas como fontes de proteína na alimentação das pessoas do lugar há anos não existem e a chegada de outras espécies, como os vegetais, principalmente as frutas não enriqueceram a alimentação da população, pois não são consumidas pelos moradores da região. O grupo compreendeu que a produção de alimentos gerou emprego para alguns, mas que para a população de uma forma geral essa plantação não se apresenta como uma alternativa alimentar, e consequentemente não trouxe benefícios do ponto de vista da soberania alimentar.

[...] há animais extintos: onça, ema, macaco, jacu, seriema, canário amarelo, avestruz, arara, guaxinim, gato do mato, tamanduá.

[...] não tinha um monte de frutas, aí apareceu, poderia gerar uma riqueza na vida das pessoas em relação a [...] terem oportunidade de se alimentar de outras coisas, de outras vitaminas, [...] então gerou emprego, mas não gerou o benefício de alimentação, porque está [produzido] aqui o produto, mas ninguém está consumindo, então, não foi uma coisa tão boa para a população.

O mapeamento participativo desvelou as percepções, sedimentou conhecimentos, propiciou a redescoberta do território e a realização de um plano de ação. A experiência vivenciada viabilizou a articulação entre desenhar os mapas e fundamentá-los no plano discursivo-analítico com base nas percepções, na leitura, na interpretação das dimensões simbólicas, que devem fazer parte da análise da situação de saúde e da tomada de decisões de como abordar as necessidades de saúde do território. As ações extrapolaram a atuação do setor saúde e a dimensão da doença, avançando na perspectiva da promoção da saúde, transpondo a barreira da focalização. No entanto, acreditamos que este processo só foi possível pela inserção de agentes sociais como os movimentos sociais, representante da Câmara Municipal, do trabalhador rural do agronegócio e usuário do SUS. Estes são agentes de transformação local implicados no processo e com grande capilaridade na atuação intersetorial.

Esse mapeamento foi formulado de forma horizontal, em que o saber sobre saúde ambiental e do trabalhador foi paulatinamente desvelado por parte de cada um no grupo, em um esforço coletivo, de maneira colaborativa, na redescoberta de um mundo, em certa medida, invisível. Barros e Sá ${ }^{19}$ reforçam que os microprocessos políticos, intersubjetivos e inconscientes vividos nos serviços de saúde interferem na produção do cuidado. Acreditamos que o mapeamento em saúde alicerçado na participação social e na determinação social do processo saúde-doença, favoreceu o reconhecimento do território e das necessidades de saúde, fortaleceu a interlocução com campo da saúde ambiental e do trabalhador no território local e avançou na superação dos processos contribuintes para a insuficiência das práticas no cotidiano da APS.

\section{Considerações finais}

O reconhecimento do território pelo grupo de pesquisa teve como catalisador inicial a aproximação com o outro - que é individual e coletivo , que tem uma história e uma cultura. Compreender a dimensão sócio-histórica do território, onde foi construída uma relação sociedade-natureza, respeitando e ou desrespeitando os limites e as potencialidades locais, a história de luta, a mobilização e o envolvimento dos agentes locais no enfrentamento e na conquista dos direitos de cidadania, pode propiciar ao setor saúde o entendimento da resistência, dos mecanismos de sobrevivência da comunidade e auxiliar a repensar as práticas de saúde instituídas com vistas à melhoria da qualidade de vida. Nesta perspectiva, a ideia de território caminharia do político para o cultural, ou seja, das fronteiras entre os povos aos limites do corpo e do afeto entre as pessoas, ensejando uma abordagem de território com boas possibilidades para as análises em saúde, particularmente para a APS, como também para o entendimento contextual do processo saúde-doença, principalmente em espaços comunitários ${ }^{20}$.

A conclusão do grupo de pesquisa-ação sobre os problemas do território e os mecanismos para abordá-los evidenciou que a sabedoria dos agentes sociais locais propiciou o reconhecimento das necessidades de saúde, priorizando efetivamente as questões, respeitando os princípios da universalidade, equidade e integralidade. A partir do mapeamento participativo em saúde ambiental e do trabalhador, o grupo de pesquisa propôs um plano, que contemplou ações intersetoriais, participativas e que extrapolam a Política Nacional de Atenção Básica. As ações abrangem o escopo das relações produção-ambiente-saúde e reforçam o papel do poder público e do controle social. Dentre as ações propostas no plano de ação do grupo, como necessárias e intervenientes na situação de saúde, com vistas a superar o processo em curso no território citamos: Criar Conse- 
lho Local Intersetorial e uma Lei Municipal que regulamente a utilização dos bens naturais para combater problemas como os desmatamentos, queimadas, dentre outras; Realizar levantamento/registro dos agravos à saúde relacionados ao trabalho que chegam à UBS; Implantar nas UBS horário noturno semanal para atender os trabalhadores; e visitar as empresas do agronegócio.

Pelo exposto, concordamos com Wimmer e Figueiredo ${ }^{21}$ no que concerne ao entendimento da proposição de ações intersetoriais, quando apontam que o engajamento dos sujeitos como coletivos organizados, possibilita o desenvolvimento de ações coletivas, propiciando intervenção na realidade local numa perspectiva de estabelecer uma educação para autonomia. A concepção do plano baseou-se na compreensão da necessidade de identificar problemas relacionados à saúde ambiental e do trabalhador e propor soluções para estes, que, em certa medida, se apresentam como um pensar contra-hegemônico. Foi fundamental no processo e para o plano o estímulo à crítica social e à compreensão de que a realidade de vida que se vivencia na pobre- za não é natural, mas reflexo da exploração social histórica gerada pelo lucro ${ }^{21}$. Esse plano demonstrou o comprometimento dos sujeitos com o agir em saúde na perspectiva defendida por Merhy $^{22}$, que propõe a construção de novos modos de agir em saúde, orientados pela lógica de uma integralidade radicalmente comprometida com a produção da vida, articulada às intenções que ambicionam um agir micropolítico como dobra de fazeres macro, como o ecologista que deve imaginar seu fazer aqui e agora, olhando para o mundo em geral e o amanhã. E por fim, acreditamos que realizar análise de situação de saúde, planejamento e organização do serviço de saúde na APS, utilizando além dos critérios epidemiológicos um mapeamento participativo em saúde ambiental e do trabalhador pode contribuir para a reorganização do serviço de saúde com vistas a garantir o acesso, o acolhimento e a identificação dos problemas de saúde decorrentes do trabalho, facilitando a percepção da dinâmica viva das relações do desenvolvimento econômico com a produção e a saúde nos territórios e sua interface com o processo saúde-doença.

\section{Colaboradores}

VM Pessoa, RM Rigotto, FF Carneiro e ACA Teixeira contribuíram em todas as fases de elaboração do manuscrito. 


\section{Referências}

1. Dias EC, Rigotto RM, Augusto LGS, Cancio J, Hoefe MGL. Saúde ambiental e saúde do trabalhador na atenção primária à saúde, no SUS: oportunidade e desafios. Cien Saude Colet 2009; 14(6):2061-2070.

2. Pessoa VM, Rigotto RM, Teixeira ACA, Pinheiro TMM. As novas necessidades de saúde nos territórios dos sertanejos do baixo Vale do Jaguaribe-Ce e os desafios à política pública de saúde. In: Rigotto RM, organizadora. Agrotóxicos, trabalho e saúde. Fortaleza: Edições UFC; 2011. p. 549-583.

3. Haesbaert R. O mito da desterritorialização: do 'fim dos territórios' à multiterritorialidade. 2a Edição. Rio de Janeiro: Bertrand Brasil; 2006.

4. Brasil. Ministério da Saúde (MS). Departamento de Atenção Básica. Política Nacional de Atenção Básica. Brasília: MS; 2006.

5. Brasil. Ministério da Saúde (MS). Departamento de Atenção Básica. Política Nacional de Promoção da Saúde. Brasília: MS; 2006.

6. Gondim GMM, Monken M, Iñiguez Rojas L, Barcellos C, P Peiter, Navarro MBMA, Gracie R. O Território da Saúde: a organização do sistema de saúde e a territorialização. In: Miranda AC, Barcellos C, Moreira JC, Monken M, organizadores. Ter ritório, Ambiente e Saúde. Rio de Janeiro: Fiocruz 2008. p. 237-256.

7. Aerts D, Alves GG, La Salvia MW, Abegg C. Promoção de saúde: a convergência entre as propostas da vigilância da saúde e da escola cidadã. Cad Saude Publica 2004; 20(4):1020-1028.

8. Goldstein RA, Barcellos C. Geoprocessamento e Participação Social: ferramentas para a vigilância ambiental em saúde In: Território, Ambiente e Saúde. Rio de Janeiro: Editora Fiocruz; 2008.

9. Breilh, J. Precisamos ter um novo viver, com taxas de crescimento menos agressivas, mas com mais qualidade. Entrevista. Escola Politécnica de Saúde Joaquim Venâncio, Fiocruz. [acessado 2012 maio 16]. Disponível em: http://www.epsjv.fiocruz.br/ index. php?Area=Entrevista\&Num $=34$

10. Minayo CS, Deslandes SF, Gomes R, organizadores. Pesquisa social: teoria, método e criatividade. 29a Edição. Petropólis: Vozes; 2010.

11. Thiollent M. Metodologia da pesquisa-ação. $16^{\mathrm{a}}$ Edição. São Paulo: Cortez; 2008.

12. Rigotto RM, Marinho AMCP, Ellery AEL, Sampaio JLF, Tupinamba SV. Da primavera silenciosa às primaveras silenciadas: conflitos socioambientais no agronegócio da fruticultura e agrotóxicos no Baixo Jaguaribe. In: Zhouri A, Laschefski K, organizadores. Desenvolvimento e conflitos ambientais. $1^{\text {a }}$ Edição. Belo Horizonte: UFMG; 2010. p. 148-175.

13. Freire P. Educação e conscientização. In: Freire P. Educação como prática da liberdade. 21 $1^{\text {a }}$ Edição. São Paulo: Paz e Terra; 1992. p. 109-130.
14. Zanotto MAC, De Rose TMS. Problematizar a própria realidade: análise de uma experiência de formação contínua. Educ Pesquisa 2003; 29(1):45-54.

15. Orlandi EP. Análise do discurso: princípios e procedimentos. Campinas: Pontes; 2000.

16. Brasil. Ministério da Saúde(MS). Conselho Nacional de Saúde. Resolução no. 196 de 10 de outubro de 1996. Diretrizes e Normas Regulamentadoras de Pesquisas Envolvendo Seres Humanos. Diário Oficial da União 1996; 16 out.

17. Carvalho HM. Os territórios da saúde e a saúde dos territórios: discutindo o processo de territorializa ção em saúde a partir do caso de um serviço de atenção primária em Porto Alegre/RS [dissertação] Porto Alegre: Universidade Federal do Rio Grande do Sul; 2003.

18. Santos AOL, Rigotto RM. Território e territorialização: incorporando as relações produção, ambien te e saúde na Atenção Básica. Trab Educ Saúde 2011; 8(3):387-406.

19. Barros DM, Sá MC. O processo de trabalho em saúde e a produção do cuidado em uma unidade de saúde da família: limites ao acolhimento e reflexos no serviço de emergência. Cien Saude Colet 2010; 15(5):2473-2482.

20. Monken M, Peiter P, Barcellos C, Iñiguez Rojas L, Navarro MBMA, Gondim GMM, Gracie R. O Território na Saúde: construindo referências para análises em saúde e ambiente. In: Miranda AC, Barcellos C, Moreira JC, Monken M, organizadores. Território, Ambiente e Saúde. Rio de Janeiro: Fiocruz; 2008. p. 23-41.

21. Wimmer GF, Figueiredo GO. Ação coletiva para qualidade de vida: autonomia, transdisciplinaridade e intersetorialidade. Cien Saude Colet 2006; 11(1):145-154.

22. Merhy EE. Integralidade: implicações em cheque. In: Pinheiro R, Ferla AA, Mattos RA. Gestão em Redes: tecendo os fios da integralidade em saúde. Rio de Janeiro: EDUCS; 2006. p. 97-109.

Artigo apresentado em 15/03/2012

Aprovado em 20/05/2012

Versão final apresentada em 26/06/2012 